\title{
QUALITY OF PROVISION OF EDUCATIONAL SERVICES IN SECONDARY EDUCATION IN UKRAINE
}

\author{
Nina Fedorova ${ }^{1}$ \\ Vasily Madzigon ${ }^{2}$ \\ Alena Malinoshevskaya ${ }^{3}$
}

DOI: https://doi.org/10.30525/978-9934-588-38-9-19

\begin{abstract}
The authors of the article analysed the new approaches to the formation of youth's life-pragmatic, economic thinking, their awareness of the laws of recent development, of the development of Ukrainian society. In this regard, the content of the educational process in general secondary education institutions (GSEI) requires significant improvement, the creation of appropriate pedagogical conditions for the education of students during the introduction of market relations. It is not an easy task and it needs scientific justifications, practical skills, suggestions, which students would take with interest. Minds of every young person must be inherited with the values of a free personality, who has social activity, critical thinking, willingness to take conscious risks, the ability to protect one's rights, and help others.

In order to obtain information about the quality of the educational process or about the system of educational services provision based on the results of the assessments, it is necessary to use independent assessment and other control methods. At the same time, it is impossible to establish a single series of universal indicators, criteria and norms for assessing the quality of the provision of educational services in secondary education. Information on the results of the provision of educational services should become a significant part of independent indicators. The analysis showed

${ }^{1} \mathrm{PhD}$ in Pedagogy, Senior Researcher,

Institute of Gifted Child of the National Academy of Pedagogical Sciences of Ukraine, Ukraine ORCID: https://orcid.org/0000-0003-4382-4686

${ }^{2}$ Doctor of Pedagogical Sciences, Professor,

Full Member of the Academy of Pedagogical Sciences of Ukraine,

Chief Employee of the Department of Innovative Technologies,

Institute of Gifted Child of the National Academy of Pedagogical Sciences of Ukraine, Ukraine

ORCID: https://orcid.org/0000-0003-0692-2500

${ }^{3} \mathrm{PhD}$ in Pedagogy, Deputy Director,

Institute of Gifted Child of the Academy of Pedagogical Sciences of Ukraine, Ukraine

ORCID: https://orcid.org/0000-0003-0472-1940
\end{abstract}


that the methodological basis is a differentiated, individual approach, as well as a personality-oriented paradigm, as well as quality indicators. To clarify this problem, the following methods are used: pedagogical diagnostics (student development, volume and depth of learning, upbringing); testing (determination of abilities, performance, projective,) observations.

\section{Introduction}

Nowadays reality requires fundamental changes in the areas of society, including the provision of educational services for the younger generation. It also requires new approaches to the formation of life-pragmatic, economic thinking among young people, their awareness of the laws of recent development, and the development of Ukrainian society. In this regard, the content of the educational process in general secondary education institutions (GSEI) requires significant improvement, the creation of appropriate pedagogical conditions for the education of students during the introduction of market relations. It is not an easy task and it needs scientific justifications, practical skills, suggestions, which students would take with interest.

Some aspects of the education of students which are covered in the works of the classics of pedagogy (Ya. Komenskyi, K. Ushynskyi, S. Rusova, V. Sukhomlynskyi, A. Makarenko, V. Davydov and others), in modern studies (V. Madzihon, V. Palamarchuk, M. Yarmachenko, A. Furman and others) as well as in practices (V. Alfimov, M. Huzyk, O. Zakharenko, T. Karpenko, A. Solohub, B. Chyzhevskyi, V. Khairulina and others) make it possible to assert the importance and necessity of improving pedagogical activities in the educational process in general secondary education institution.

Today, the main task of education in Ukrainian secondary school is the formation of a new way of students' thinking in the transient information space, in the conditions of market relations, as well as during the construction of a sovereign and independent Ukraine. Minds of every young person must be inherited with the values of a free personality, who has social activity, critical thinking, willingness to take conscious risks, the ability to protect one's rights, and help others. And here it is appropriate to recall the statement of the outstanding physicist of the 20th Century Albert Einstein, who proclaimed that "Try not to succeed, but so that your life makes sense."

Today in Ukraine, assessing the quality of the effectiveness of educational services in general secondary education institution should be ensured 
by obtaining objective information about the level of their provision. It is known that a single control does not make it possible to reveal a complete picture of the preparedness of the student. In order to obtain information about the quality of the educational process or about the system of educational services provision based on the results of the assessments, it is necessary to use independent assessment and other control methods. At the same time, it is impossible to establish a single series of universal indicators, criteria and norms for assessing the quality of the provision of educational services in secondary education. Information on the results of the provision of educational services should become a significant part of independent indicators. This should include conceptual factors (city, district, village, settlement, etc., socio-economic status of the student's family, characteristics of the institution of general secondary education, etc.); factors implemented in the resources invested in education (the amount of funds spent on one student, material base, etc.); factors characterizing the applied curricula and technologies for the provision of educational services (curricula, technologies, class filling, forms of differentiation and individualization of the provision of educational services, etc.); as well as indicators of the results of educational services (the results of test work, the percentage of graduates from general secondary education institutions and graduates entering higher education institutions and by the percentage engaged in professional activities).

\section{Analysis of recent research and publications}

It should be noted that the quality of education is determined today quite ambiguously, and this is due to the fact that the concept of "quality" is multifaceted. So, M. Montessori in her education system used to determine the quality of purpose and content. The concept of "quality of education" in schools was first investigated at the system level by S. Shishova, and V. Kalney (1998). Today, an important link in the quality management of education system is standards. They determine the content of education, record the requirements for the assimilation of educational material at the level of the sequence of subjects content and their assimilation [3, p. 22].

The aim of the article is to highlight educational technologies that improve the quality of the provision of educational services to secondary school students. 


\section{Research methods}

The study will use a set of methods: theoretical (analysis of research sources, comparison, classification, synthesis of research results, generalization and systematization of scientific data); empirical (observation, structured interviews, questionnaires, document analysis, online testing); methods of mathematical data processing with their subsequent qualitative interpretation and meaningful generalization.

\section{The results of the study}

The main idea of the study is that the use of control, pedagogical diagnostics and testing will improve the quality of the provision of educational services, and the result of these actions will increase the quality of knowledge of students in general secondary education institution. V. Bondar (2005) defines the functions and principles of academic achievement assessment:

- educational - subject knowledge; educative - the development of personality traits (mastery of self-control techniques, integrity, activity, accuracy and the like;

- developing - self-esteem, analysis, synthesis, classification, systematization, mental activity and the like;

- managerial - willingness to learn new things, identify the causes of difficulties, formation of motives for studying;

- motivationally stimulating - assessment of educational achievements, improvement of one's own results, objectivity, etc.;

- consistency - need to carry out pedagogical analysis, from primary perception to the practical application of knowledge in each subject;

- transparency - compliance with the uniform requirements and criteria for assessing the knowledge, skills, experience, acquisition of self-evaluation, etc.

The methodological basis is a differentiated, individual approach, as well as a personality-oriented paradigm.

Reflecting the requirements for the mandatory minimum of knowledge and skills, the standard is used as a sample for comparing the results of education in various institutions and teaching staff, as well as students who received information about modern educational systems [1, p. 22-25]. Based on this, we can formulate quality indicators; according to common features we divide them into the following groups: 
- the first one is a group, which depends on territorial and administrative factors that change over time; the content of the provision of educational services and curricula; forms and methods of organizing the educational process; conditions for interaction with the external environment; the use of pedagogical technologies for the provision of educational services; teachers' satisfaction and motivation; composition, satisfaction and motivation of students; type of general secondary education institution (urban, district, rural, etc.); socio-economic environment;

- the second one is a group which is more general for the educational system of one level: standardization, variability of curricula; organization of the provision of educational services; compliance of the structure and content of education with the relevant trends in the theory and practice of the provision of educational services; use of traditional, non-traditional and information technologies and control; the availability of material support (textbooks, ICT, control system, additional classes, etc.);

- the third one, namely the quality of the final product is clearly defined: the level of preparedness such as: the sum of knowledge, skills; personal development; competencies and value-semantic relations to education; information on the social activities of graduates and their personnel growth.

Therefore, the entry of Ukrainian education (including secondary) into the European space caused the problem of revising traditional methods of monitoring the effectiveness of the quality of the provision of educational services in Ukraine's education, including secondary. If under the conditions of authoritarian upbringing, just control over the quality of knowledge of student was analysed, then under the new conditions it is necessary to analyse the joint activities of the student and teacher. Therefore, to clarify this problem, it is necessary to use other methods, namely, pedagogical diagnostics, which provide a unifying way of obtaining information about the results of the provision of educational services and the implementation of the educational process. To this end, the tasks of analysing these processes and results include:

- development of students (readiness to receive educational services, the pace of the formation of mental functions, achieving gradual accumulation of knowledge, etc.);

- the volume and depth of learning (the provision of educational services), the ability to use the acquired knowledge, skills, the level of formation of the basic methods of thinking, creative activity, and the like; 
- upbringing (level of upbringing, depth of moral beliefs of behaviour, etc.).

With the help of control, it is possible to define that the student completed the tasks correctly, and the teacher appreciated it perfectly. Diagnostics, on the contrary, shows that an excellent assessment of students' knowledge is the result of a good memory, and not of the development of intellectual sphere, and the formation of mental activity. So, a broader meaning is included in the diagnostic method than in the traditional test of knowledge.

In diagnostics, various methods are used. Along with traditional methods (control, verification, assessment, accounting of knowledge, skills), the methods like testing, research of potential students' abilities (learning ability), design of an individual and personality-oriented educational process are applied. Diagnosing helps the teacher to determine how much time and effort are necessary to achieve certain qualities.

Diagnostics subordinates traditional methods of control to a humanistic goal and directs them to new student relationships. Not so much the purpose of monitoring and evaluating knowledge and skills is changing, as their influence on the consciousness, feelings and behaviour of students. Therefore, the teacher today must have modern diagnostic techniques, and actively try to master them.

Testing is the most objective diagnostic technique. The concept of "test" (of English origin) is defined as a trial, verification. In our understanding, the concept of "test" is correctly formulated in the following - it is a system of techniques for testing and evaluating individual mental traits and properties of a person; the task in a standard form, the implementation of which should reveal the presence of certain knowledge, skills, abilities or other psychological characteristics - interests, emotional reactions, and the like. Unlike other types of scientific research, tests are characterized by the following qualities: 1) the relatively simple procedure and the necessary equipment; 2) the direct record of the results; 3) the possibility to be used both individually and for entire groups; 4) the convenience of mathematical processing; 5) the short period of time; 6) the presence of established standards (norms) .... Test assessment is relative. It indicates only the place that the researcher occupies according to the relevant norm .... Three types of tests are more common in pedagogy: the first is the determination of abilities, which, as a rule, make it possible relatively to measure the level 
of development of psychological and pedagogical properties (memory, thinking, imagination, etc.) which determine the success of an activity. The second is the determination of success, which usually makes it possible to determine the degree of readiness for a certain activity, that is, they measure the level of knowledge, skills necessary for a particular activity. The third one is projective, which is more often aimed at establishing the presence of mental properties in a particular person [2, p. 455].

Diagnostics considers the results in connection with the paths, ways to achieve them, identifies trends, the dynamics of the formation of products. Diagnostics contains control, verification, assessment, accumulation of statistical data, analysis, identification of dynamics, prediction of further developments.

So, for example [5, p. 127-128], modern expert in didactics offers to conduct classes in such options lasting for 20, 30, 35, 45 minutes. Teachers of the laboratory school agreed to conduct classes at the primary level for 35 minutes. This corresponds to the psychophysical properties of the development of students and considers that primary school students can concentrate attention on the subject of study for only 15 minutes. It also helps to observe the hygiene of mental activity and to increase the level of working capacity, and it requires the teacher not only to know the age characteristics, but also to have deep pedagogical experience and professionalism. As practice has shown, this has a positive effect on student performance, which has been increasing every year, as can be seen from Table 2 , student performance tends to increase. This can be demonstrated at (see Fig. 1), where the academic years are taken as the abscissa axis, and the percentage of student knowledge as the ordinate axis (see Figure 1) [6, p. 127-128].

The lower graph shows the quality of knowledge of students in grades 5-7, and the upper one shows the quality of knowledge of students in grades 1-3.

Thus, the tasks of pedagogical control over the quality of the provision of educational services to students of general secondary education institutions are the following: analysis of the processes and results of students' development (readiness to receive educational services, pace of formation of mental functions, etc.); analysis of the processes and results achieved in obtaining educational services (volume, depth, ability to apply knowledge in practice, the level of formation of methods of thinking, mastery of creative activities, etc.). Pedagogical diagnostics is considered as the simul- 


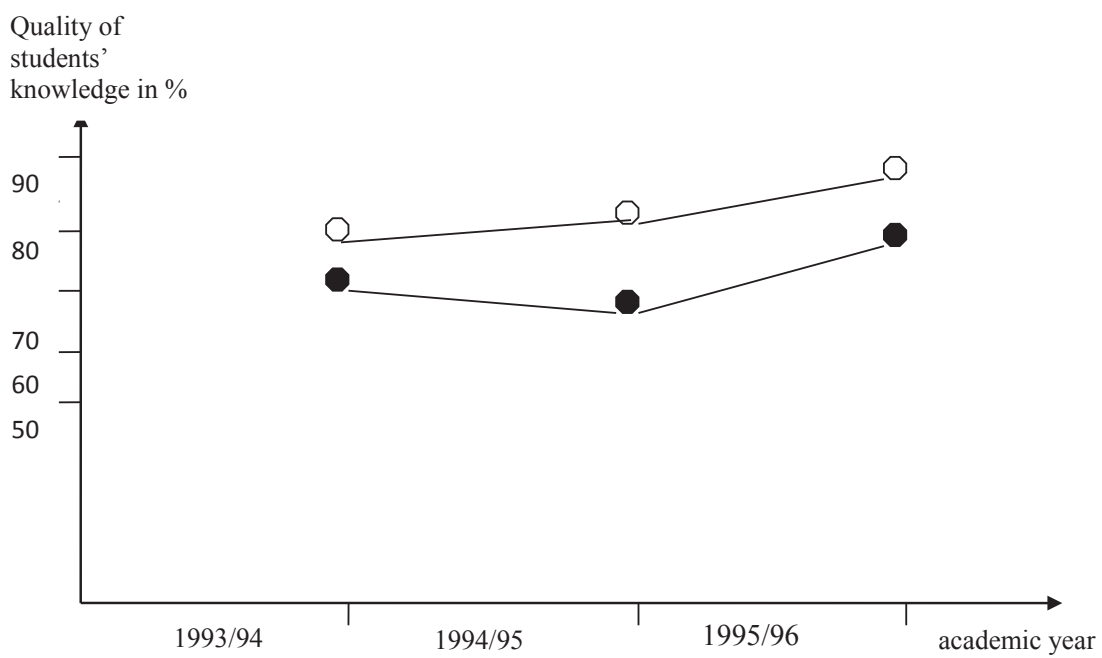

Figure 1. Quality of students' knowledge

taneous operational study and evaluation, regulation and correction of a process or phenomenon at the level of the student, the activity of a teacher or the head of a general secondary education institution. The introduction of pedagogical diagnostics into the practice of pedagogical teams gives the opportunity to scientifically substantiate the secondary educational institution, which lays the foundations of a qualitative system of educational services. Therefore, pedagogical diagnostics provides the proper feedback through the mediation of diagnostic evaluation in order to make the right management decision.

Authors T. Shamova, P. Tretyakova, N. Kapustina identify three main stages of diagnosing certain phenomena in the educational process.

The first stage is the previous specified diagnostics. It mainly requires the use of an observation method. This method allows to obtain initial information about the nature of the interaction of teachers with students and parents, the content of the educational process, its focus on the socialization and individualization of student development. The second one - clarifying diagnostics - is applied to more objective data formed on the basis of the complex use of different methods of pedagogical diagnostics. At this stage, it is advisable to conduct various conversations, surveys, questionnaires for 
teachers and parents, timing of students' day schedules, study of pedagogical and medical records. Pedagogical diagnostics at this stage is combined with psychological one, which requires interaction with the psychologist.

Third stage - the final diagnostics - contains data of generalized character obtained at the previous stages, but in their comparison and referencing. At this stage, the method of "expert evaluation" is mainly used. It allows to reveal the professional activity of the teacher, to reveal the satisfaction of the parents with the quality of the provided services, to assist the teachers and parents in educating the students, to identify the success of mastering curricula and so on. Therefore, the choice of diagnostic methods depends on the purpose of diagnoses.

In general, pedagogical diagnoses do not involve long-term research and complex tools. Next, we explain some types of pedagogical diagnostics.

Observations [2, p. 439] of various aspects of the educational process make it possible to obtain specific factual material about the state of education and provision of educational services, about the interaction of a student and a teacher. Therefore, this method is essential in pedagogical diagnostics. Observation technology involves the following algorithm of action: determination of purpose and tasks of observation (to identify the effectiveness of innovative technology, the success of its assimilation, the nature of individual activity, etc.); choice of object, subject and situation (what to observe, when it is advisable in order not to intervene the educational process); the choice of observation method (openness, closeness from the student, within the activity of the teacher and students or out of it, in time, repetition); the choice of the method of recording the results of the observation (record in the form of protocol, forms and card technologies, voice recorder, camera, etc.); analysis of the information received, its expert evaluation.

Observation is the simplest method of pedagogical diagnostics, but its effectiveness may be poor in the absence of a program and because of technology disruption. Today, there exist examples of observation cards. Here is an example (see Table 1) [3, p. 53-55].

Analysis of the information received will require highlighting the main and establishing the causes and dependencies. Moreover, a systematic approach to the analysis of the educational process, in which the activities of the teacher and students are interconnected, is important. Expert assessment 
Table 1

Card to analyse theconditions for the educational process

\begin{tabular}{|c|l|l|l|l|}
\hline No & \multicolumn{1}{|c|}{ Object of observation } & Advantages & Disadvantages & Notes \\
\hline 1. & $\begin{array}{l}\text { Execution of educational } \\
\text { process. }\end{array}$ & & & \\
\hline 2. & $\begin{array}{l}\text { Availability of equipment in the } \\
\text { classroom. }\end{array}$ & & & \\
\hline 3. & $\begin{array}{l}\text { Location and storage of material } \\
\text { equipment. }\end{array}$ & & & \\
\hline 4. & $\begin{array}{l}\text { Compliance with the rules for } \\
\text { equipment application. }\end{array}$ & & & \\
\hline 5. & $\begin{array}{l}\text { Selection of equipment } \\
\text { according to the subject of the } \\
\text { lesson. }\end{array}$ & & & \\
\hline 6. & $\begin{array}{l}\text { Relationship with other } \\
\text { activities. }\end{array}$ & & & \\
\hline 7. & $\begin{array}{l}\text { Development of a responsibility } \\
\text { for equipment storage and the } \\
\text { ability to keep order. }\end{array}$ & & & \\
\hline
\end{tabular}

Source: developed by L. Pozdnyak

is based on the assessment of the severity of the indicator: very high, high, sufficient, takes place, weak, absent. A possible grading system may be the following: 0 points - an unacceptable level (there is no indicator) 1 point a critical level (indicator is poorly expressed) 2 points - an acceptable level (indicator is stable) 3 points - an optimal level (indicator is pronounced).

The score system allows you to calculate the estimated indicator, determined by the formula: $\mathrm{N}=\mathrm{N} *$ : Nmax, where $\mathrm{N} *$ is the sum of the points obtained in the assessment; Nmax - the maximum possible number of points. The indicator of $75 \%$ and above is the optimal significance; $50 \%-$ and above - permissible significance; $40 \%$ and below is a critical level.

Today, the process of organizing quality in material production has been successfully applied in the field of education, science and culture.

The adaptation of these methods of general management makes it possible to determine the main types of activities of the general secondary education institution in ensuring quality: quality planning: identifying users (students, teachers, parents, specialists of organizations, etc.); clarifying the needs of users; development of educational curricula; bringing plans to ex- 
ecution; establishing quality relationships: activities; the means to ensure the provision of educational services by teachers; student enrollment; organization of the educational process in accordance with standards; a set of indicators and quality criteria; quality control: providing means and procedures for measuring quality indicators; analysis and monitoring; correcting the process in accordance with standards; creating conditions for improving user participation in control procedures; quality improvement: creating infrastructure for the continuous process of providing educational services; identification and elimination of the causes of deficiencies; the creation of educational and methodological groups to improve the provision of educational services and provide motivation for their activities; establishing control over the achievement of the educational goal; ensuring continuity of professional development of teaching staff; certification of the provision of educational services: achieving a high level and competitiveness; recognition of the success of a specific general secondary education institution by the customer.

\section{Pedagogical testing}

In secondary education, tests are also used: for general mental abilities, mental development; special abilities; learning ability, success, good breeding, achievements. to determine individual qualities (memory, thinking, character, etc.); to determine the level of education (the formation of universal, moral, social and other qualities). For testing including pedagogical one, it is necessary to comply with the relevant laws and principles of the educational process that contain a specific character and are shown in Figure 2 [7, p. 36-39].

The core of the conceptual apparatus of pedagogical testing contains three main subordinate concepts: a) tasks in a test form; b) test task; c) pedagogical test.

1) Tasks in a test form contain a question, tasks, exercises, which are not used in tests. The answers to them are ambiguous and verbose to reveal truth. They require a lot of intellectual energy. At the same time, tasks in test form provide for a clear and fast differentiation of correct / incorrect answers. Mastery of the test form is an important prediction of test development and a mandatory requirement for developers. The choice of form should be determined by the content of the task and the type of controlling knowledge. 


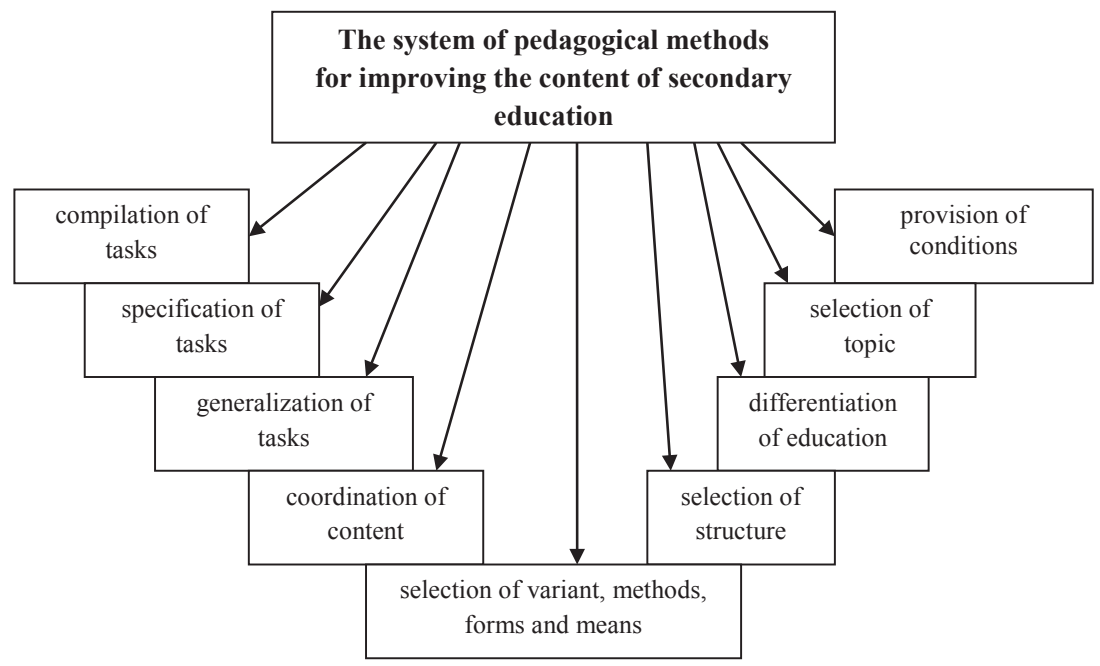

Figure 2. The system of methods to improve the content of the general secondary education institution

2). The test task is not made of tasks in a test form, but of test tasks. The main statistical requirements for test tasks are the following: a) of known complexity; b) of differentiated ability; c) of a positive correlation of points with the total points of the entire text.

The complexity of the task is defined ambiguously: a) mentally visual is based on the estimated number and nature of mental operations necessary to complete the task; b) after empirical testing of the problem, with the calculation of the proportion of incorrect answers (the higher it is, the more difficult the task). Tasks of intermediate difficulty should also be included in the test. The differentiated ability of the test task is understood by its ability to separate weak and strong students. The more difficult the task, the smaller the group of correctly answered ones.

Test task forms can be: 1) with the choice of one or more correct answers; 2) in open form; 3 ) to establish compliance; 4) to establish the correct sequence; 5) with the choice of one correct answer; 6) with the choice of several correct answers. 
The pedagogical test is fully defined as a system of representative parallel tasks with increased complexity, of a specific form, and allows to qualitatively and effectively measure the level and structure of students' preparedness. Thus, pedagogical tests can be used in pedagogical practice for this purpose: ranking students within the testing group; professional or other selection according to specified criteria; identifying knowledge gaps.

\section{Example I.}

\section{Choose the correct answer}

1, Personality is:

1) a person who has a high consciousness:

2) an adult;

3) an intelligent, free, responsible person;

4) a person who consciously manages his own behaviour and activity.

2. Development is:

1) the accumulation of quantitative changes in the human body;

2) the destruction of something old and the emergence of something new;

3) a purposeful process to develop specified qualities in people;

4) quantitative and qualitative changes in the body that occur over time under the influence of various factors.

3). What qualities do parents share?

1) type of nervous system, makings, skin colour;

2) ways of thinking, willpower, perseverance, purposefulness;

3) eye colour, social experience;

4) traits, character.

4) What does the development of the student's abilities and talents mainly depend on?

1) on the number of books read;

2) on the range of acquired knowledge, skills and abilities;

3) on natural inclinations, organization of the educational process;

4) on communication with peers.

5) Why does a teacher need to know the age characteristics of children?

1) it enables teachers to see the growth and development of the biological fund of human;

2) it is an accurate scheme of mental development of the child according to which the universal means of education are developed and applied; 
3 ) it makes real sense, since all his methods of education are based on knowledge of individual characteristics;

4) the teacher studies the individual characteristics of children, which then considers in the process of educational activities.

Circle the correct answer (with pencil or pen).

Example II.

\section{Solve a pedagogical problem}

1. The abilities of children .... Some parents speak with extraordinary ease about them: "My Volodya has such abilities! He does his homework "off the cuff" and in some subjects does not read anything. But he only gets " 11 " and " 12 ". If he was studying ...

a) Which features can be used to judge the student's abilities?

b) Are parents 'judgments about the child's abilities objective?

c) Hard work and development of abilities. How are they connected? Give an example.

2. Yurko is 10 years old. He returned back home tired, hungry, and satisfied ... It turns out, that he and his friends have been shovelling snow away for two hours: "We helped the janitor. You know, he's old, it's hard for him. There is so much snow!" Mother's eyes are getting warm. And Yurko runs to the hall and take out a hryvnia from his jacket: "Here, I have got one, and Tolik also has got one!" Mom is unpleasantly concerned; "So you were helping for money?" she asked desperately, "No, we weren't, but he has given us money when we finished.»

a) Has the janitor chosen the right form of gratitude?

b) How would you react as a mother? Justify the answer.

\section{Example III.}

\section{Range}

1. Develop a thematic plan for a psychologist to interview senior students.

2. Benjamin Franklin (1706-1790) - an outstanding American educator and statesman, one of the authors of the Declaration of Independence of the USA, while he was young created "system of charity" with the relevant guidelines. At the end of the week, he noted cases of their violation. Here is this system:

- restraint. Eat and drink with measure;

- silence. Say only the words which can benefit me or others; 
- order. It is necessary to put things in place: to have a special place and time for each class;

- determination. You have to do what you have planned or intended to do;

- hard-working. You do not need to waste time: you need to be constantly busy with something useful: you need to give up unnecessary actions and contacts;

- sincerity. It is impossible to lie; it is necessary to have clear thoughts;

- moderation. It is necessary to avoid extremes;

- cleanliness. It is necessary to keep neatness in clothing and in residence;

- calmness It is not necessary to worry about the insignificant things;

- modesty. Etc.

Rank the items of the "system of charity" starting with the more important ones for you. Make your own image of yourself.

For current and final control of the quality of knowledge, as well as for appraisal of students, it is advisable to use complex tasks in a test form [7, p. 36-39).

Therefore, modern society is a society of profound changes, of constant creative evolution, which is affected by mechanisms that combine macro(social) factors and micro- (individual) factors, which are not predictable and often radically new. The pace of development of modern society depends on the creative efforts of the individual, on the opportunities and abilities that he possesses. Thus, globalization stimulates the activity of the individual, indicates the need to prepare him or her for the future, sets new goals and objectives for the education system.

The use of the intellectual potential of the individual, and the development of a strategy for intensive knowledge acquisition are among the most important goals and objectives of educational policy throughout the world community. To achieve these goals, it is necessary to mobilize scientists and teachers in preparing the personality, which is able to be integrated into the modern high-tech world of knowledge and information.

Therefore, an important link in the quality management of education system covers:

1) adherence to certain standards in order to provide students with deep fundamental knowledge of the subjects;

2) application of control, pedagogical diagnostics and testing;

3) definition of functions and principles for evaluation of educational achievements. 
In combination, this will give the opportunity to improve the quality of the provision of educational services to students in general secondary education. Considering the aforementioned components will certainly lead to successful results.

Thus, this implies that, in relation to the provision of educational services in secondary education, the basic quality management methodology must be fully in line with generally accepted principles and be used to ensure it. In the following articles, we will continue to look for techniques that should enhance the provision of educational services in secondary education.

\section{References:}

1. Bolotov V.A., Yefremov N.F. (2007). Sistemy otsenki kachestva obrazovaniya [The system for assessing the quality of education]. Moscow: Universitetskaya kniga: Logos. (in Russian)

2. Honcharenko S.U. (2011). Ukrainskyi pedahohichnyi entsyklopedychnyi slovnyk [Ukrainian pedagogical encyclopedic dictionary]. Rivne: Volynski oberehy. (in Ukrainian)

3. Krulekht M.V., Tel'nyuk I.V. (2007). Sistemy otsenki kachestva obrazovaniya [Education Quality Assessment Systems]. Moscow: Universitetskaya kniga, Logos. (in Russian)

4. Neumann Yu.M., Khlebnikov V.A. (2000). Introduction to the theory of modeling and parameterization of pedagogical tests. Moscow: Prometheus: Logos. (in Ukrainian)

5. Fedorova N.F. (1999). Orhanizatsiino-pedahohichni umovy diialnosti shkoly-laboratorii naukovoi ustanovy [Organizational and pedagogical conditions of activity of a school-laboratory of a scientific institution]. Candidate's thesis. Kyiv: Instytut pedahohiky APN Ukrainy. (in Ukrainian)

6. Fedorova N.F., Danylenko L.I. (1999). Orhanizatsiia diialnosti shkoly-laboratorii naukovoi ustanovy [Organization of activity of school-laboratory of scientific institution]. Kyiv: Lohos. (in Ukrainian)

7. Piontkovskyi-Vykhvaten B., Fedorova N. (2017). Hotuiemo profesionaly dlia derzhavy - Ukraina [We prepare professionals for the state - Ukraine]. Kyiv: IOD NAPN Ukrainy. (in Ukrainian) 